\title{
Allocation of maize varieties according to temperature for use in mechanical kernel harvesting in Ningxia, China
}

\author{
Hongyan $\mathrm{Li}^{1,2}$, Yonghong Wang ${ }^{3}$, J un Xue ${ }^{1,2}$, Ruizhi Xie ${ }^{1,2}$, Keru Wang ${ }^{1,2}$, Rulang Zhao ${ }^{3}$, \\ Wanmao Liu ${ }^{1,2}$, Bo Ming ${ }^{1,2}$, Peng Hou ${ }^{1,2}$, Zhentao Zhang ${ }^{1,2}$, Wenjie Zhang ${ }^{3}$, Shaokun Li,2* \\ (1. Institute of Crop Sciences, Chinese Academy of Agricultural Sciences, Beijing 100081, China; \\ 2. Key Laboratory of Crop Physiology and Ecology, Ministry of Agriculture and Rural Affairs, Beijing 100081, China; \\ 3. Crop Research Institute of Ningxia Academy of Agriculture and Forestry Sciences, Yinchuan 750105, China)
}

\begin{abstract}
The reasonable assessment of maize varieties in different ecological regions can allow temperature resources to be fully exploited and reach the goal of high yield and efficiency and is thus an important direction of modern maize development in China. In this study, a logistic power nonlinear growth model was used to simulate the accumulated temperature required for kernel dehydration to moisture contents of $25 \%, 20 \%$, and $16 \%$ for various maize cultivar, which were divided into six types based on the accumulated temperature required for kernel dehydration to a moisture content of $25 \%$. The relationship between the yield of maize cultivars and the accumulated temperature required for kernel dehydration to a moisture content of $25 \%$ was found to follow a unary function model. Changing the planted maize variety was found to increase economic returns by more than $7000 \mathrm{RMB} / \mathrm{hm}^{2}$ in Ningxia, Northwest China. Under the conditions of mechanical grain harvesting, economic benefits can be further increased by means of selecting high yields and fast-dehydrating varieties, selling when the grain dehydration is below $16 \%$. A better way to achieve grain dehydration to a moisture content below $16 \%$ is to postpone the harvest date as much as possible rather than drying after the harvest at physiological maturity. The areas of various types of maize varieties can be dehydrated to moisture contents of $25 \%, 20 \%$, and $16 \%$ were marked. Based on the distribution of heat resources in different regions of Ningxia from the normal sowing date to October 31 before winter irrigation, the appropriate cultivars for various regions in the province were determined based on production benefits. Therefore, in different areas of Ningxia, selecting suitable maize varieties according to temperature resources can reach a high yield and mechanical kernel harvesting, and ultimately obtain higher economic benefits.
\end{abstract}

Keywords: maize, dehydration, grain yield, economic return, mechanical kernel harvesting DOI: $10.25165 /$ j.ijabe.20211401.6035

Citation: Li H Y, Wang Y H, Xue J, Xie R Z, Wang K R, Zhao R L, et al. Allocation of maize varieties according to temperature for use in mechanical kernel harvesting in Ningxia, China. Int J Agric \& Biol Eng, 2021; 14(1): 20-28.

\section{Introduction}

Technology for the mechanical harvesting of maize kernels is being rapidly promoted in China. The moisture content of maize kernels has an important effect on the benefits of mechanical kernel-harvesting ${ }^{[1,2]}$. The quality of maize kernels is inversely related to their moisture content. Additionally, kernels with a

\section{Received date: 2020-07-24 Accepted date: 2020-10-22}

Biographies: Hongyan $\mathbf{L i}$, Master, research interest: maize mechanization production, Email: Lhy200_1@163.com; Yonghong Wang, Professor, research interest: maize physiology and ecology, Email: wyhnx2002-3@163.com; Jun Xue, $\mathrm{PhD}$, research interest: maize lodging resistance, Email: xuejun5519@126.com; Ruizhi Xie, PhD, Professor, research interest: maize physiology and ecology, Email: xieruizhi@caas.cn; Keru Wang, PhD, Professor, research interest: maize mechanization production, Email: wangkeru@caas.cn; Rulang Zhao, Master, research interest: maize physiology and ecology, Email: langzi9620@126.com; Wanmao Liu, PhD candidate, research interest: maize physiology and ecology, Email: 15026232318@163.com; Bo Ming, PhD, Associate Professor, research interest: efficient utilization of environmental resources in crop production systems, Email: mingbo@caas.cn; Peng Hou, PhD, Associate Professor, research interest: physiology and ecology of maize high yield cultivation, Email: houpeng@caas.cn; Zhentao Zhang, PhD candidate, research interest: crop physiology and ecology, Email: zhangzhentao@, cau.edu.cn; Wenjie Zhang, Master, research interest: maize physiology and ecology, Email: zwj870131@163.com.

*Corresponding author: Shaokun Li, PhD, Professor, research interest: physiology and ecology of maize high yield and high efficiency cultivation. Institute of Crop Sciences, Chinese Academy of Agricultural Sciences, Beijing 100081, China. Tel: +86-10-82108891, Email: lishaokun@caas.cn. high moisture content have a low unit sale price, high drying $\operatorname{costs}^{[3]}$, and are difficult to transport and store. Therefore, lowering the moisture content of maize kernels at harvest time is key for improving the benefits and quality of maize harvesting.

Compared to the United States, the grain moisture content of maize at harvest is high in China. Generally, Chinese maize is mechanically harvested at moisture contents of $20 \%-28 \%{ }^{[4]}$. The broken rate is often less than the Chinese national standard of $\leq 5 \%$ (GB/T-21962-2008) when the kernel moisture content is $15 \%-25 \%$; meanwhile, the broken rate is the lowest when the kernel moisture content is $20 \%{ }^{[5]}$. According to a report on the quality of maize kernels by the US Grain Council, from 2011 to 2019, the moisture content of harvested maize kernels in the United States averaged $16.4 \%$. Most farms in the United States reduce the cost of kernel drying by ventilating at low temperature in autumn and winter ${ }^{[6]}$.

Maize variety and temperature are the key factors that influence maize kernel dehydration ${ }^{[7-12]}$. The change of kernel moisture content with accumulated temperature can be simulated by the Logistic Power nonlinear growth model ${ }^{[13]}$. In the mechanical harvesting of maize kernels, some early-maturing and fast-dehydrating varieties are being widely adopted in China. Early-maturing cultivars require less accumulated temperature between sowing and physiological maturity ${ }^{[14]}$. Additionally, the dehydration rate of early-maturing cultivars is faster than that of late-maturing cultivars. However, the yield of late-maturing cultivars is generally higher than that of early-maturing cultivars. Nevertheless, early-maturing cultivars require less dehydration 
time in the field after physiological maturity ${ }^{[15]}$. Therefore, maize varieties with high yield and a fast dehydration rate are suitable for mechanical kernel harvesting.

China has a large maize planting region with large differences in accumulated temperature, radiation, and precipitation. Therefore, the reasonable assessment of maize varieties to make full use of temperature resources and reach the goal of high yield and efficiency is an important direction of modern maize development in China. The Ningxia Hui Autonomous Region (NHAR) is located in the arid region of Northwest China. The low-altitude areas in the north and the middle of the region are irrigated agricultural areas where the accumulated temperature of $\geq 0^{\circ} \mathrm{C}$ from April to October is up to $4100^{\circ} \mathrm{C} \cdot \mathrm{d}$; the high-altitude areas in the south are dry-farming regions with $2900^{\circ} \mathrm{C} \cdot \mathrm{d}$ minimum accumulated temperature of $\geq 0^{\circ} \mathrm{C}$ from April to October. Therefore, Ningxia can represent the temperature conditions of the main maize growing areas in China. The north and middle of Ningxia can represent the maize cropping pattern in the irrigated agricultural area of Northwest China.

Studies have shown that there are significant differences in the rate of grain dehydration for maize varieties with very similar growth periods. Therefore, in this study, the indicator of growth period was abandoned and used the accumulated temperature requirement of variety's dehydration to $25 \%$ as the criterion for the variety's dehydration type was used. This work aimed to answer the following rarely studied questions: (1) What is the relationship between the accumulated temperature demand for dehydration to $25 \%$ and the yield? (2) In production, how much do economic benefits differ between maize varieties with different dehydration types? and (3) How much does the economic benefit change between high-moisture grain harvest and low-moisture grain harvest?

In this study, a Logistic Power nonlinear growth model was used to simulate the accumulated temperature that is required to dehydrate the kernels of various maize cultivars to a moisture content of $25 \%$. Additionally, the cultivars were classified by $200^{\circ} \mathrm{C} \cdot \mathrm{d}$ as the gradient in order to match the various types with accumulated temperature resources. The classification results reflect the dehydration characteristics of the studied cultivars. The economic benefits of various types of maize varieties were calculated based on total production investment and total grain sales value. A univariate function model was used to simulate the relationship between yield and the accumulated temperature demand for maize grain dehydration to a moisture content of $25 \%$ and calculated the difference in economic benefits between different varieties. Additionally, the economic benefits per hectare of high-moisture maize kernels after drying was calculated. Furthermore, the saved drying costs of maize kernels by naturally drying in the field after physiological maturity was calculated. Further, we determined the regions in Ningxia in which various types of maize varieties can be dehydrated to moisture contents of $25 \%, 20 \%$, and $16 \%$ under normal sowing conditions. Based on the test results, we recommend varieties high yield and low lodging rate varieties to be planted in each region in Ningxia. These results will promote the development of mechanized maize-kernel harvesting technology in China. Additionally, they are of great significance for promoting the current transformation of Chinese maize from high moisture at harvest $(\geq 25 \%)$ to low moisture at harvest ( $\geq 20 \%$ ), which is important to increasing the economic benefits of maize grain harvesting technology. This study could be an important reference for other regions to achieve mechanical grain harvesting.

\section{Materials and methods}

\subsection{Experimental design}

The experiment was conducted in 2017-2019. In 2017 and 2018 , a total of 38 locally grown maize cultivars were planted in the Yongning test base of the Ningxia Academy of Agriculture and Forestry Sciences in the NHAR. A total of 19 cultivars were planted in 2017 and a total of 30 were planted in 2018, with 11 cultivars in common between the two years (Table 1). The row spacing was $60 \mathrm{~cm}$ and the planting density was 90000 plants $/ \mathrm{hm}^{2}$. The method of field management was the same as the local production. Etoxazole and lambda-cyhalothrin were sprayed once during the period between silking and physiological maturity. A total of 250 single-ear plants of maize without pests were selected before the silking. The ears were bagged until the filaments had grown to $2-3 \mathrm{~cm}$. Then, after the bags were removed, the plants were jiggled to achieve full pollination. The moisture content of the kernels in the middle of the ear was measured at intervals of 5$7 \mathrm{~d}$ beginning on the 10th day after pollination. The moisture content of the kernels was measured at an interval of 2-3 d when the plants were close to physiological maturity. The disappearance of the milk line and the formation of a black layer on the surface of the kernels were used as indicators of physiological maturity. The experiments were terminated on September 27 in 2017 and October 30 in 2018. In 2019, a total of three plots were added, one in Yingchuan City, one in Lingwu City, and one in Pingluo County, planting 3-5 cultivars of maize in each plot. Then, the kernel moisture content and broken rate of the harvested kernels were measured in Yingchuan, Lingwu and Pingluo (Table 1). The data of average air temperature during the growing season (from April 1 to October 31) in 2008-2018 in Yinchuan were obtained from the National Weather Service Network of China. The average air temperature during the 2017 and 2018 growing seasons is normal level (Figure 1).

Table 1 Maize cultivars investigated in this study

\begin{tabular}{|c|c|c|c|c|}
\hline Year & Site & Cultivars & Plot area & Sowing date \\
\hline 2017 & Yinchuan & $\begin{array}{l}\text { Lianchuang } 825 \text { (LC825), MC670, Denghai } 618 \text { (DH618), Denghai } 739 \text { (DH739), Denghai } 769 \text { (DH769), } \\
\text { Denghai } 786 \text { (DH786), M751, Denghai } 105 \text { (DH105), Lianchuang } 808 \text { (LC808), Liaodan } 575 \text { (LD575), } \\
\text { Liaodan } 585 \text { (LD585), Liaodan 586 (LD586), Shaandan } 628 \text { (SD628), Zengyu 1572 (ZY1572), Zhengdan } \\
528 \text { (ZD528), Heyu } 187 \text { (HY187), Nonghua } 213 \text { (NH213), Zhengdan } 1002 \text { (ZD1002), Shandan } 620 \text { (SD620) }\end{array}$ & $72.0 \mathrm{~m}^{2}$ & Apr. 20 \\
\hline 2018 & Yinchuan & $\begin{array}{l}\text { M751, Dika } 519 \text { (DK519), Huamei } 1 \text { (HM 1), LC 825, NH213, Xianyu } 335 \text { (XY335), DH739, Dongdan } 1331 \\
\text { (DD1331), Jidan } 66 \text { (JD66), LD575, Ruipu } 909 \text { (RP909), Yinyu } 123 \text { (YY123), DH769, Dongdan } 6531 \\
\text { (DD6531), Jingnongke 728 (JNK728), LD585, SD620, Yinyu } 274 \text { (YY274), Dika } 517 \text { (DK517), Fuyou } 968 \\
\text { (FY968), Lidan 295 (LD295), LD586, Xianyu } 1321 \text { (XY1321), Yinyu } 439 \text { (YY439), ZY1572, Zhengdan } 958 \\
\text { (ZD958), KX9384, Demeiya 1 (DMY 1), Demeiya } 2 \text { (DMY 2), DH786 }\end{array}$ & $72.0 \mathrm{~m}^{2}$ & Apr. 28 \\
\hline 2019 & $\begin{array}{l}\text { Lingwu } \\
\text { Pingluo } \\
\text { Yinchuan }\end{array}$ & $\begin{array}{l}\text { KX9384, DK517, YY274 } \\
\text { KX9384, DK517, YY274 } \\
\text { KX9384, DK517, YY274, XY335, YY439 }\end{array}$ & $\begin{array}{l}5.0 \mathrm{hm}^{2} \\
5.0 \mathrm{hm}^{2} \\
3.3 \mathrm{hm}^{2}\end{array}$ & $\begin{array}{l}\text { Apr. } 14 \\
\text { Apr. } 24 \\
\text { Apr. } 20\end{array}$ \\
\hline
\end{tabular}




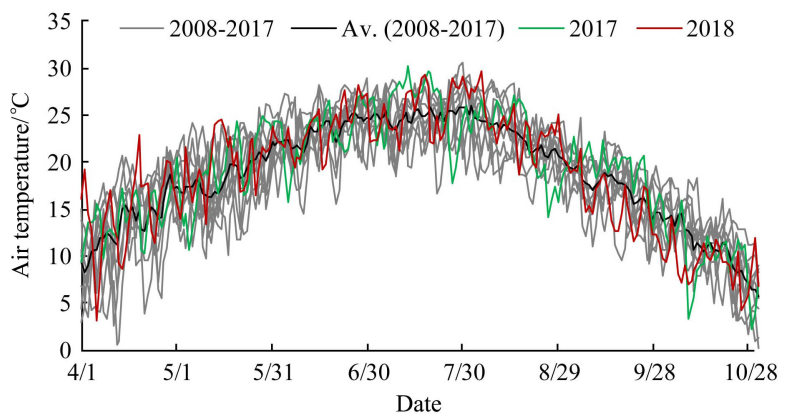

Figure 1 Average of air temperatures during the growing season in 2008-2018 in Yinchuan

\subsection{Sampling and measurements}

\subsubsection{Kernel moisture content}

Five ears were removed from each cultivar and the kernels in the middle of the ear were removed. A total of 100 fresh kernels were weighed before and after drying in an oven at $85^{\circ} \mathrm{C}$ in order to calculate their moisture content. Three replicates were performed for each cultivar. The kernel moisture content was calculated as follows:

$$
M C=\frac{W F-W D}{W F} \times 100 \%
$$

where, $M C$ is the kernel moisture content, $\%$; WF is the fresh weight of kernel, g; WD is the dry weight of kernel, $g$.

\subsubsection{Grain yield}

At harvest, an area of $18 \mathrm{~m}^{2}(10 \mathrm{~m}$ long $\times 3$ rows $)$ was harvested manually from the three middle rows. Kernel number per ear was measured using 20 randomly selected ears from each sampling area. Kernel weight was determined by counting 1000 kernels in triplicate. Grain yield was expressed at a grain water content of $14 \%$. The grain yield was calculated as follows:

$$
Y=\frac{W F_{\text {ears }} \times P K \times(1-M C)}{(1-14 \%)}
$$

where, $Y$ is the grain yield, $\mathrm{kg} / \mathrm{hm}^{2} ; W F_{\text {ears }}$ is the fresh weight of ears per hectare, $\mathrm{kg} / \mathrm{hm}^{2} ; P K$ is the percentage of kernels, \%.

\subsection{Determination of the dehydration equation of maize cultivars}

According to the methods of Li et al. ${ }^{[13]}$ and Daynard ${ }^{[16]}$, a Logistic Power nonlinear growth model (hereinafter referred to as the dehydration model) was used to simulate the dehydration process of the maize kernels. The accumulated temperature after silking was the independent variable and the kernel moisture content was the dependent variable. Using the nonlinear curve-fitting function of the Curve Expert Professional 2.2 software, the optimal estimates of the $b$ and $c$ parameters for the regression models of different cultivars were obtained ${ }^{[13]}$. The coefficient of determination $\left(R^{2}\right)$ was used to evaluate the performance of the models, and the dehydration equation (Equation (3)) of the maize kernels was determined ${ }^{[17]}$. The 11 cultivars which were used during both 2017 and 2018 were used to test the applicability of the dehydration model. The measured kernel moisture contents for 2017 were used to validate the 2018 kernel dehydration model. The dehydration model is as follows:

$$
M C_{d}=\frac{a}{1+\left(\frac{T}{b}\right)^{c}}
$$

where, $M C_{d}$ is the dynamic kernel moisture content, \%; $T$ is the accumulated temperature after pollination $\left(\geq 0^{\circ} \mathrm{C}\right.$ accumulated temperature), ${ }^{\circ} \mathrm{C} \cdot \mathrm{d}$; and $a, b$, and $c$ are model parameters; $a$ was a model extreme value and was set to 90 in this study.

\subsection{Calculation of economic return}

The maize variety economic return is as follows:

$$
y=Y i \times P-E i
$$

where, $Y i$ is the variety yield at $14 \%$ moisture content, $\mathrm{kg} / \mathrm{hm}^{2}$; and $P$ is the unit price of maize kernels with a moisture content of $14 \%$, which has a value of $1.977 \mathrm{RMB} / \mathrm{kg}$ (2019); Ei is the extra investment which is required for fertilizers, irrigation pesticides, etc., and has a value of $14175 \mathrm{RMB} / \mathrm{hm}^{2}$ (based on 2019 data); Ei includes: machinery operating cost $\left(4410 \mathrm{RMB} / \mathrm{hm}^{2}\right)$, irrigation equipment cost (1015 RMB $\left./ \mathrm{hm}^{2}\right)$, pesticide cost $\left(1015 \mathrm{RMB} / \mathrm{hm}^{2}\right)$, fertilizer cost $\left(3225 \mathrm{RMB} / \mathrm{hm}^{2}\right)$, seed cost $\left(1170 \mathrm{RMB} / \mathrm{hm}^{2}\right)$, labor cost (3270 RMB $\left./ \mathrm{hm}^{2}\right)$, and drying cost (0-0.04 RMB $\left./ \mathrm{kg}\right)$.

When the variety has changed the economic return was assessed using the following equation:

$y=\Delta T \times a \times P-(Y i+\Delta T \times a) \times \Delta D c-(Y i+\Delta T \times a) \times \Delta P g-\Delta E i$ where, $a$ is the increase in yield due to an increase in accumulated temperature of $1{ }^{\circ} \mathrm{C} \cdot \mathrm{d}, \mathrm{kg} /\left({ }^{\circ} \mathrm{C} \cdot \mathrm{d}\right) ; \Delta T$ is the change of accumulated temperature, ${ }^{\circ} \mathrm{C} \cdot \mathrm{d} ; P$ is the unit price of maize kernel with a moisture content of $14 \%, \mathrm{RMB} / \mathrm{kg}$; the range of $P$ was set to $1.977 \mathrm{RMB} / \mathrm{kg}$ in the NHAR (based on 2019 data); $Y i$ is the variety yield at $14 \%$ moisture content, $\mathrm{kg} / \mathrm{hm}^{2} ; \Delta D c$ is the increase in drying cost due to the increase in kernel moisture content that is caused by changing from low-yield cultivars to high-yield cultivars, $\mathrm{RMB} / \mathrm{kg}$; the range of $\Delta D c$ was set to $0.01-0.04 \mathrm{RMB} / \mathrm{kg}$ (based on 2019 data); $\Delta P g$ is the decrease in the sales order price that is caused by a grade drop; the range of $\triangle P g$ was set to $0-1.0 \mathrm{RMB} / \mathrm{kg}$ (based on 2019 data); $\Delta E i$ is the change of $E i$ when the cultivar is changed.

\subsection{Accumulated temperature calculation and variety recommendation}

By combining $T$ with the temperature data from 2008 to 2017 , the locations were marked on a map of Ningxia, China various types of maize varieties can be dehydrated to moisture contents of $25 \%, 20 \%$, and $16 \%$ under normal sowing conditions. Based on the test results, varieties with a high yield and low lodging rate were recommended to be planted in each area in Ningxia.

$$
T=T i+T s
$$

where, $T$ is the accumulated temperature from the sowing date to kernel dehydration to a certain kernel moisture content; $T i$ is the required accumulated temperature from pollination to dehydration to achieve the target kernel moisture content simulated by the dehydration model; $T s$ is the required accumulated temperature from sowing to silking.

\subsection{Data calculation and plot}

The Microsoft Excel 2016 software was used to calculate the data of kernel dehydration, harvested kernel quality, etc.; the Sigmaplot 12.5 software (Systat Software Inc., San Jose, California, USA), Excel 2016, and ArcGIS software (Esri, Redlands, California, USA) were used to plot data; the SPSS 17.0 software (IBM, Armonk, New York, USA) was used to perform statistical analysis and significance tests; and the Curve Expert Professional 2.2 software was used to estimate the model parameters.

\section{Results}

\subsection{Applicability test for kernel dehydration model}

For the 38 tested cultivars, the minimum accumulated temperature requirement from seeding to physiological maturity was $2720.5^{\circ} \mathrm{C} \cdot \mathrm{d}$ (cultivar Demeiya 2 ), the highest accumulated temperature was $3542.7^{\circ} \mathrm{C} \cdot \mathrm{d}$ (cultivar Shaandan 628) and the average accumulated temperature was $3274.3^{\circ} \mathrm{C} \cdot \mathrm{d}($ Table 2). The kernel moisture content at harvest was between $26.0 \%$ (cultivar Xianyu335) and 35.7\% (cultivar Shaandan 628), with an average 
value of $30.1 \%$. The value of $b$ parameter in the dehydration equation was between 929.69 and 1259.35, with an average value of 1058.50. The value of $c$ parameter of the dehydration equation was between 1.58 and 2.29 , with an average value of 1.97 .

Table 2 Maize cultivars accumulated temperature requirements during the seeding to physiological maturity and the parameters $b$ and $c$ of the kernel dehydration equation (Equation (3))

\begin{tabular}{|c|c|c|c|c|c|c|}
\hline \multirow[b]{2}{*}{ Cultivar } & \multicolumn{2}{|c|}{$\begin{array}{c}\text { Accumulated } \\
\text { temperature } /{ }^{\circ} \mathrm{C} \cdot \mathrm{d}\end{array}$} & \multirow{2}{*}{$\begin{array}{c}\text { Kernel } \\
\text { moisture } \\
\text { content at } \\
\text { physiological } \\
\text { maturity } / \%\end{array}$} & \multicolumn{3}{|c|}{ Parameters } \\
\hline & $\begin{array}{l}\text { Sowing } \\
\text { to } \\
\text { silking }\end{array}$ & $\begin{array}{l}\text { Sowing to } \\
\text { physiological } \\
\text { maturity }\end{array}$ & & $\mathrm{b}$ & $\mathrm{c}$ & $R^{2}$ \\
\hline Dongdan 1331 & 1747.6 & 3290.6 & 34.9 & 1152.34 & 2.14 & $0.98 * *$ \\
\hline Lidan 295 & 1747.6 & 3276.2 & 30.7 & 1056.31 & 2.08 & $0.98 * *$ \\
\hline Xianyu 1321 & 1802.1 & 3435.8 & 30.9 & 1031.71 & 1.75 & $0.96 * *$ \\
\hline Denghai 739 & 1626.7 & 3315.7 & 31.3 & 1158.03 & 1.85 & $0.98 * *$ \\
\hline Lianchuang 825 & 1755.9 & 3406.4 & 31.4 & 1084.38 & 1.91 & $0.96^{* *}$ \\
\hline Liaodan 585 & 1756.4 & 3445.0 & 31.5 & 1105.63 & 1.99 & $0.96^{* *}$ \\
\hline Zengyu 1572 & 1741.5 & 3385.6 & 31.6 & 1121.54 & 1.78 & $0.98 * *$ \\
\hline Shandan 620 & 1686.8 & 3295.2 & 31.7 & 1033.18 & 1.80 & $0.96 * *$ \\
\hline Zhengdan 958 & 1747.6 & 3360.6 & 32.0 & 1069.31 & 1.88 & $0.99 * *$ \\
\hline Zhengdan 528 & 1707.1 & 3450.1 & 33.6 & 1139.29 & 1.71 & $0.96^{* *}$ \\
\hline Liaodan 586 & 1741.5 & 3414.9 & 33.6 & 1112.54 & 1.86 & $0.97 * *$ \\
\hline Denghai 105 & 1735.9 & 3309.1 & 33.7 & 1068.99 & 1.68 & $0.98 * *$ \\
\hline Shaandan 628 & 1765.1 & 3542.7 & 35.7 & 1259.35 & 1.58 & $0.98 * *$ \\
\hline Неуu 187 & 1656.0 & 3194.7 & 31.8 & 1073.01 & 2.12 & $0.98 * *$ \\
\hline Denghai 786 & 1503.7 & 3025.9 & 31.7 & 1015.00 & 1.96 & $0.98 * *$ \\
\hline MC670 & 1679.0 & 3237.6 & 30.3 & 1115.97 & 2.29 & $0.98 * *$ \\
\hline Dongdan 6531 & 1718.7 & 3138.2 & 29.5 & 992.16 & 2.00 & $0.98 * *$ \\
\hline Jidan 66 & 1620.0 & 3235.3 & 26.6 & 1005.61 & 2.01 & $0.98 * *$ \\
\hline Demeiya 1 & 1372.8 & 2861.6 & 26.7 & 939.03 & 2.10 & $0.98 * *$ \\
\hline KX9384 & 1450.9 & 3107.0 & 27.7 & 1031.86 & 2.19 & $0.98 * *$ \\
\hline Huamei 1 & 1548.1 & 3079.9 & 28.9 & 1036.87 & 2.29 & $0.98 * *$ \\
\hline Nonghua 213 & 1713.3 & 3273.6 & 28.9 & 1004.03 & 2.02 & $0.96^{* *}$ \\
\hline Yinyu 274 & 1644.4 & 3100.6 & 29.1 & 1005.47 & 2.20 & $0.99 * *$ \\
\hline Jingnongke 728 & 1666.4 & 3034.9 & 29.2 & 937.71 & 2.11 & $0.99 * *$ \\
\hline Ruipu 909 & 1666.4 & 3230.3 & 29.3 & 1027.65 & 2.00 & $0.97 * *$ \\
\hline Demeiya 2 & 1344.6 & 2720.5 & 29.5 & 929.69 & 2.07 & $0.99 * *$ \\
\hline Fuyou 968 & 1747.6 & 3277.4 & 28.0 & 999.13 & 2.10 & $0.97 * *$ \\
\hline Xianyu 335 & 1644.4 & 3309.7 & 26.0 & 1006.10 & 2.00 & $0.96^{* *}$ \\
\hline Zhengdan 1002 & 1679.0 & 3456.6 & 27.3 & 1146.80 & 1.81 & $0.99 * *$ \\
\hline Dika 519 & 1747.6 & 3345.4 & 27.6 & 977.00 & 1.97 & $0.97 * *$ \\
\hline Yinyu 439 & 1691.1 & 3440.6 & 27.9 & 1069.55 & 1.81 & $0.97 * *$ \\
\hline Yinyu 123 & 1718.7 & 3371.0 & 28.6 & 1041.34 & 2.00 & $0.98 * *$ \\
\hline M751 & 1699.1 & 3413.8 & 28.8 & 1099.74 & 2.01 & $0.97 * *$ \\
\hline Dika 517 & 1691.1 & 3299.0 & 28.8 & 999.33 & 2.07 & $0.97 * *$ \\
\hline Lianchuang 808 & 1735.9 & 3441.4 & 29.4 & 1115.85 & 1.70 & $0.99 * *$ \\
\hline Liaodan 575 & 1699.1 & 3290.4 & 29.5 & 1024.51 & 2.01 & $0.97 * *$ \\
\hline Denghai 769 & 1638.0 & 3285.6 & 30.0 & 1105.61 & 2.10 & $0.98 * *$ \\
\hline Denghai 618 & 1655.9 & 3323.7 & 30.0 & 1131.19 & 2.05 & $0.99 * *$ \\
\hline Maximum & 1802.1 & 3542.7 & 35.7 & 1259.35 & 2.29 & 0.99 \\
\hline Minimum & 1344.6 & 2720.5 & 26.0 & 929.69 & 1.58 & 0.96 \\
\hline Average & 1670.9 & 3274.3 & 30.1 & 1058.50 & 1.97 & 0.98 \\
\hline
\end{tabular}

Note: $* *$ indicates significance at the $p<0.01$ level.

The results of the test of the applicability of the dehydration model show that $R^{2}=0.98(n=137)$ and the root-mean-square error $(R M S E)=3.41$. Therefore, the applicability of the dehydration model was proven (Figure 2).

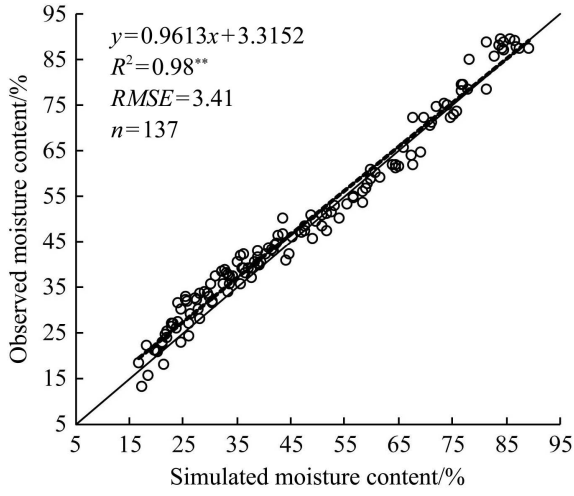

Note: $y$ is the observed moisture content, $\% ; x$ is simulated moisture content, $\%$ ** indicates significance at the $p<0.01$ level. $R^{2}$ : coefficient of determination; RMSE: root-mean-square error.

Figure 2 Difference between the measured and predicted maize kernel moisture content

\subsection{Classification of maize cultivars}

The yield of the 38 studied maize cultivars ranged from $12635 \mathrm{~kg} / \mathrm{hm}^{2}$ to $19091 \mathrm{~kg} / \mathrm{hm}^{2}$, with an average value of $16147 \mathrm{~kg} / \mathrm{hm}^{2}$ (Table 3). The accumulated temperature required for kernel dehydration to a moisture content of $25 \%$ was between $2820.2^{\circ} \mathrm{C} \cdot \mathrm{d}$ and $4068.6^{\circ} \mathrm{C} \cdot \mathrm{d}$, and was below $3800^{\circ} \mathrm{C} \cdot \mathrm{d}$ for 37 of the 38 cultivars. Starting at $2800^{\circ} \mathrm{C} \cdot \mathrm{d}$, the maize cultivars were divided into six types - namely types I, II, III, IV, V, and VI-based on the gradient of the accumulated temperature of $200^{\circ} \mathrm{C} \cdot \mathrm{d}$. The cultivars required accumulated temperatures of between $3048.3^{\circ} \mathrm{C} \cdot \mathrm{d}$ and $4544.6^{\circ} \mathrm{C} \cdot \mathrm{d}$ for kernel dehydration to $20 \%$ and between $3294.1{ }^{\circ} \mathrm{C} \cdot \mathrm{d}$ and $5080.0^{\circ} \mathrm{C} \cdot \mathrm{d}$ for dehydration to $16 \%$. The accumulated temperature required for kernel dehydration to a moisture content of $20 \%$ was below $4000^{\circ} \mathrm{C} \cdot \mathrm{d}$ for cultivars of types $\mathrm{I}-\mathrm{IV}$, and that required for dehydration to a moisture content of $16 \%$ was below $4000^{\circ} \mathrm{C} \cdot \mathrm{d}$ for cultivars of types I-III.

\subsection{Relationship between yield and dehydration to $25 \%$} accumulated temperature

The fitted relationship between the yield $\left(\mathrm{kg} / \mathrm{hm}^{2}\right)$ and the accumulated temperature $\left({ }^{\circ} \mathrm{C} \cdot \mathrm{d}\right)$ required between sowing and kernel dehydration to a moisture content of $25 \%$ for cultivars of types I-III is $y_{2}=6.4581 x-4911.3\left(R^{2}=0.24 * *, n=19\right)$, where $y$ is the yield and $x$ is the accumulated temperature required for kernel dehydration to a moisture content of $25 \%$ (Figure 3). Among

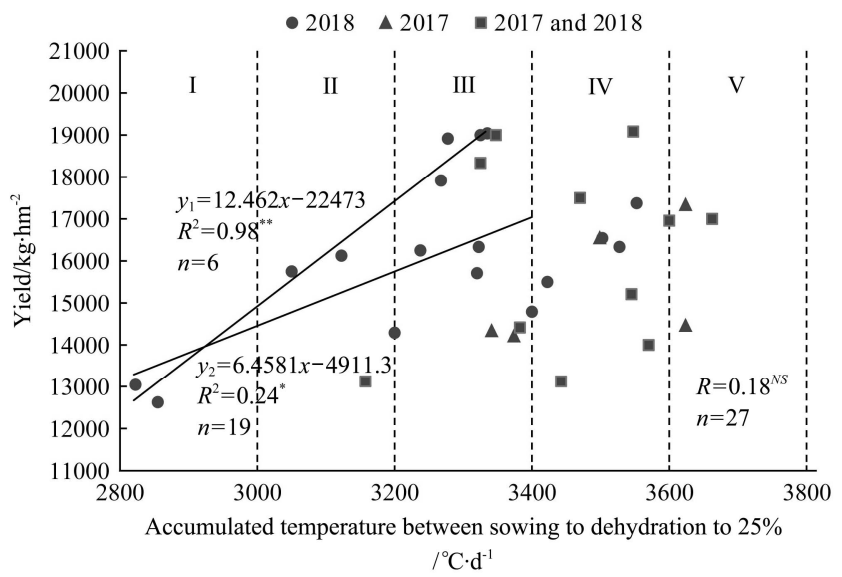

Note: I, II, III, IV, V are types I, II, III, IV and V maize cultivars, respectively. ${ }^{*}$ and ${ }^{* *}$ represent significance at the $p<0.05$ and $p<0.01$, respectively. NS: not significant at the $p<0.05$.

Figure 3 Relationship between the yield and the accumulated temperature required for dehydration to a kernel moisture content of $25 \%$ for various maize cultivars 
these cultivars, the two cultivars with the highest yields of each type were selected. For these cultivars, the fitted equation for the same relationship as above was $y_{1}=12.462 x-22473\left(R^{2}=0.98\right.$, $n=6$ ). No significant correlation was found between the yield and the accumulated temperature required for kernel dehydration to a moisture content of $25 \%$ for cultivars of types III-V.

Table 3 Accumulated temperature required for various degrees of kernel dehydration and yields for different maize cultivars

\begin{tabular}{|c|c|c|c|c|c|}
\hline \multirow{2}{*}{ Type and at range $/{ }^{\circ} \mathrm{C} \cdot \mathrm{d}$} & \multirow{2}{*}{ Cultivar } & \multirow{2}{*}{$\begin{array}{l}\text { Yield } \\
/ \mathrm{kg} \cdot \mathrm{hm}^{-2}\end{array}$} & \multicolumn{3}{|c|}{ Predicted $\mathrm{AT} /{ }^{\circ} \mathrm{C} \cdot \mathrm{d}$} \\
\hline & & & Dehydration to $\mathrm{MC}$ of $25 \%$ & Dehydration to $\mathrm{MC}$ of $20 \%$ & Dehydration to MC of $16 \%$ \\
\hline \multirow{3}{*}{$\begin{array}{c}\mathrm{I} \\
(2800-3000)\end{array}$} & Demeiya 2 & 13051.0 & 2820.2 & 3048.3 & 3294.1 \\
\hline & Demeiya 1 & 12635.2 & 2852.3 & 3077.1 & 3318.9 \\
\hline & Average & 12843.1 & 2836.3 & 3062.7 & 3306.5 \\
\hline \multirow{6}{*}{$\begin{array}{c}\text { II } \\
(3000-3200)\end{array}$} & KX9384 & 15764.3 & 3048.1 & 3280.5 & 3529.2 \\
\hline & Huamei 1 & 16156.7 & 3121.7 & 3339.7 & 3571.6 \\
\hline & Jingnonek 728 & - & 3140.5 & 3363.2 & 3602.6 \\
\hline & Denghai 786 & 13109.9 & 3156.4 & 3427.7 & 3721.0 \\
\hline & Yinyu 274 & 14299.1 & 3197.4 & 3422.3 & 3662.7 \\
\hline & Average & 14832.5 & 3132.8 & 3366.6 & 3617.4 \\
\hline \multirow{14}{*}{$\begin{array}{c}\text { III } \\
(3200-3400)\end{array}$} & Jidan 66 & 16288.7 & 3236.2 & 3493.3 & 3771.4 \\
\hline & Xianyu 335 & 17928.5 & 3265.1 & 3524.2 & 3804.7 \\
\hline & Dika 517 & 18924.4 & 3276.4 & 3521.1 & 3784.7 \\
\hline & Dongdan 6531 & 15739.0 & 3317.3 & 3573.0 & 3849.8 \\
\hline & Fuyou 968 & 16351.2 & 3320.8 & 3559.3 & 3815.8 \\
\hline & Nonghua 213 & 18325.7 & 3324.3 & 35779.6 & 3855.5 \\
\hline & Ruipu 909 & 19018.6 & 3323.7 & 3589.3 & 3876.9 \\
\hline & Dika 519 & 19066.8 & 3333.2 & 3591.0 & 3870.6 \\
\hline & Heyu 187 & 14340.0 & 3341.1 & 3595.1 & 3868.0 \\
\hline & Liaodan 575 & 18984.1 & 3346.9 & 3609.5 & 3893.6 \\
\hline & MC670 & 14242.5 & 3374.3 & 3609.8 & 3860.3 \\
\hline & Denghai 769 & 14410.6 & 3380.9 & 3646.0 & 3931.2 \\
\hline & Yinyu 123 & 14799.9 & 3398.8 & 3668.4 & 3960.4 \\
\hline & Average & 16801.5 & 3326.1 & 3581.5 & 3857.1 \\
\hline \multirow{13}{*}{$\begin{array}{c}\text { IV } \\
(3400-3600)\end{array}$} & Lidan 295 & 15507.4 & 3420.1 & 3677.2 & 3954.0 \\
\hline & Shandan 620 & 13142.4 & 3442.0 & 3756.5 & 4102.5 \\
\hline & M751 & 17483.1 & 3469.2 & 3751.8 & 4057.5 \\
\hline & Yinyu 439 & 16562.4 & 3501.9 & 3824.2 & 4178.3 \\
\hline & Denghai 618 & 16569.0 & 3498.3 & 3785.1 & 4094.3 \\
\hline & Zhengdan 958 & 16357.9 & 3524.5 & 3828.5 & 4160.8 \\
\hline & Liaodan 585 & 15188.7 & 3545.1 & 3833.9 & 4146.8 \\
\hline & Dongdan 1331 & 17394.4 & 3550.3 & 3819.5 & 4108.3 \\
\hline & Denghai 739 & 13989.4 & 3569.2 & 3908.4 & 4280.0 \\
\hline & Xianyu 1321 & - & 3581.3 & 3910.0 & 4273.1 \\
\hline & Liaodan 586 & 16955.9 & 3599.3 & 3920.5 & 4272.1 \\
\hline & Lianchuang 825 & 19091.5 & 3546.2 & 3848.4 & 4177.9 \\
\hline & Average & 16203.8 & 3520.6 & 3822.0 & 4150.5 \\
\hline \multirow{6}{*}{$\begin{array}{c}\mathrm{V} \\
(3600-3800)\end{array}$} & Denghai 105 & 14469.0 & 3622.6 & 3987.3 & 4393.1 \\
\hline & Zhengdan 1002 & 17343.0 & 3624.0 & 3971.4 & 4353.3 \\
\hline & Zengyu 1572 & 16983.5 & 3660.9 & 4010.1 & 4395.1 \\
\hline & Lianchuang 808 & - & 3695.1 & 4070.1 & 4486.6 \\
\hline & Zhengdan 528 & - & 3698.7 & 4076.5 & 4495.6 \\
\hline & Average & 16265.2 & 3660.3 & 4023.1 & 4424.7 \\
\hline VI $(\geq 4000)$ & Shaandan 628 & - & 4068.6 & 4544.6 & 5079.9 \\
\hline Total & Average & 16147.3 & 3399.8 & 3685.3 & 3996.1 \\
\hline
\end{tabular}

Note: “-” means quantity not measured; AT: Accumulated temperature; MC: Moisture content.

\subsection{Cultivar types and economic returns}

It was found that the increase in production caused by a $1{ }^{\circ} \mathrm{C} \cdot \mathrm{d}$ rise in the accumulated temperature required for kernel dehydration to a moisture content of $25 \%$ led to an increase in economic return of $12.74 \mathrm{RMB} / \mathrm{hm}^{2}(a=6.4581, P=1.977 \mathrm{RMB} / \mathrm{kg}, \Delta D c=0$,
$\Delta P g=0, \Delta E i=0$, based on Equation (5)). The results of this study suggest that, if the maize in the Yellow River irrigation area in the northern NHAR was harvested at the end of October, the kernel moisture content of type I cultivars would be about $14 \%$, and the kernels could therefore be directly stored in warehouses. Meanwhile, 
the kernel moisture content of type III cultivars would be about $16 \%-18 \%$. The maximum rise in economic return caused by an increase of $1{ }^{\circ} \mathrm{C} \cdot \mathrm{d}$ in the accumulated temperature required for kernel dehydration to a moisture content of $25 \%$ is $24.30 \mathrm{RMB} / \mathrm{hm}^{2}$ $(a=12.462, P=1.977 \mathrm{RMB} / \mathrm{kg}, \Delta D c=0, \Delta P g=0, \Delta E i=0)$.

Furthermore, the results suggested that replacing type I cultivars with type III cultivars could increase the economic benefits by $7553 \mathrm{RMB} / \mathrm{hm}^{2}$ (based on Equation (4), Table 4). The economic benefits were approximately equal between type III and type V. Therefore, maize cultivars with accumulated temperatures required for dehydration to a kernel moisture content of $25 \%$ of less than $3400^{\circ} \mathrm{C} \cdot \mathrm{d}$ can be mechanically harvested.

Table 4 Economic returns of different maize cultivar types in different planting regions $\left(\mathrm{RMB} / \mathrm{hm}^{2}\right)$

\begin{tabular}{|c|c|c|c|c|c|c|c|c|c|c|}
\hline Cultivar type & Huinong & Yinchuan & Zhongning & Taole & Zhongwei & Tongxin & Yanchi & Haiyuan & Guyuan & Xiji \\
\hline I & 11216 & 11216 & 11216 & 11216 & 11216 & 11216 & 11216 & 10985 & 10985 & - \\
\hline II & 16969 & 16969 & 16969 & 16969 & 16969 & 16941 & 16941 & - & - & - \\
\hline III & 18739 & 18739 & 18739 & 18739 & 18739 & 18739 & 18588 & - & - & - \\
\hline IV & 17003 & 16859 & 17003 & 16859 & 16859 & 16859 & - & - & - & - \\
\hline V & 18920 & 18920 & 18920 & 18920 & - & - & - & - & - & - \\
\hline
\end{tabular}

Note: “-” means that mechanical harvesting is unsuitable in this region. Economic returns are calculated based on Equation (7).

\subsection{Matching of cultivars in the condition of the mechanical} kernels harvesting

The sowing date and accumulated temperature from sowing to 31 October were surveyed in 10 sites of the NHAR to assess the appropriateness of the maize cultivars for mechanical kernel harvesting (Table 5). At these sites, the sowing date was from April 8 to 12 and the accumulated temperature of sowing to October 31 was between $2851.0^{\circ} \mathrm{C} \cdot \mathrm{d}$ and $3943.5^{\circ} \mathrm{C} \cdot \mathrm{d}$.

Table 5 Sowing dates and effective accumulated temperature of sowing to October 31 for the experimental sites in the Ningxia Hui Autonomous Region

\begin{tabular}{lcc}
\hline \multicolumn{1}{c}{ Site } & Sowing date & Accumulated temperature $/{ }^{\circ} \mathrm{C} \cdot \mathrm{d}$ \\
\hline Huinong & April 8 & 3943.5 \\
Yinchuan & April 8 & 3918.7 \\
Zhongning & April 12 & 3924.4 \\
Taole & April 8 & 3804.6 \\
Zhongwei & April 12 & 3727.6 \\
Tongxin & April 12 & 3702.2 \\
Yanchi & April 12 & 3529.8 \\
Haiyuan & April 10 & 3173.0 \\
Guyuan & April 8 & 3127.2 \\
Xiji & April 8 & 2851.0 \\
\hline
\end{tabular}

In general, in the Huinong, Taole, Yinchuan, Zhongning, Zhongwei, and Tongxin sites of the Yellow River irrigation area, cultivars of type I-IV (i.e., a total of 32 cultivars) could be dehydrated to a kernel moisture content of $25 \%$ by the end of October. Of these, 27 cultivars were investigated for lodging rate and yield. Of these 27, five cultivars-namely M751, Dika 517, Dika 519, Dongdan 1331, and Liaodan 586-are recommended for planting. In this region, cultivars of types I-III (i.e., a total of 20 cultivars) could be dehydrated to a kernel moisture content of below $20 \%$ before the end of October; among them, 17 cultivars were investigated for lodging rate and yield, and, based on this, cultivars Dika 517 and Dika 519 are recommended for planting. Cultivars of types I and II could be dehydrated to kernel moisture content of below 16\%. Cultivar KX9384 was recommended among the six cultivars which were investigated for lodging rate and yield in type I and type II. In Yanchi County, the planting of type I cultivars could allow dehydration to kernel moisture contents of below $16 \%$, the planting of type II cultivars could allow dehydration to below $20 \%$, and the planting of type III cultivars could allow dehydration to below 25\%. Moreover, the results suggest that in southern Haiyuan County and Guyuan City the planting of type I cultivars could allow dehydration to a kernel moisture content of below $20 \%$, which would facilitate mechanical kernel harvesting. Therefore, we recommend the planting of cultivars Dika 517 and Dika 519 in Yanchi County and the planting of cultivars Demeiya 1 and Demeiya 2 in southern Haiyuan County and Guyuan City (Figure 4).

\subsection{Moisture content and broken rate of harvested kernels}

The moisture content and broken rate of the mechanically harvested maize kernels were investigated at the end of October in Lingwu City, Pingluo County, and Yinchuan City. For the three experimental sites, cultivars of types II, III and IV could be dehydrated to $14.6 \%-24.2 \%$ (Table 6). Among the 11 sets of data, 8 sets of data have a grain crushing rate lower than $5 \%$, and 3 sets of data have a crushing rate higher than $5 \%$. Therefore, postpone the harvest period with reducing grain moisture content for mechanical harvesting is advantageous.

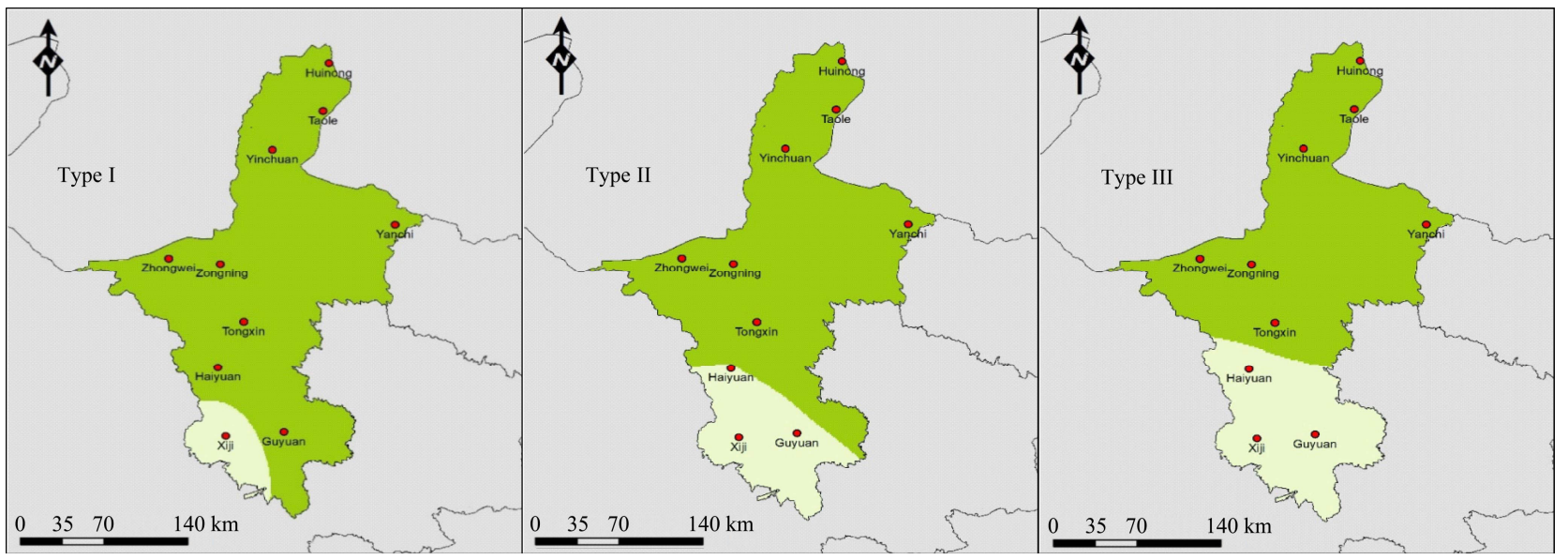




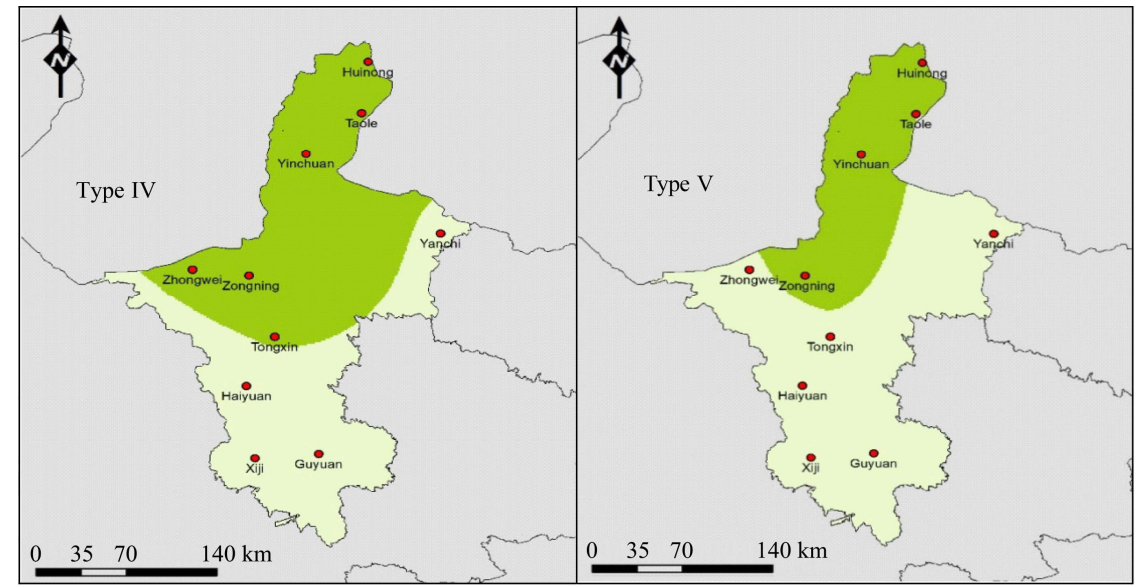

a. Distribution map of different types cultivars maize kernels dehydration to $25 \%$ in the Ningxia Hui Autonomous Region, China

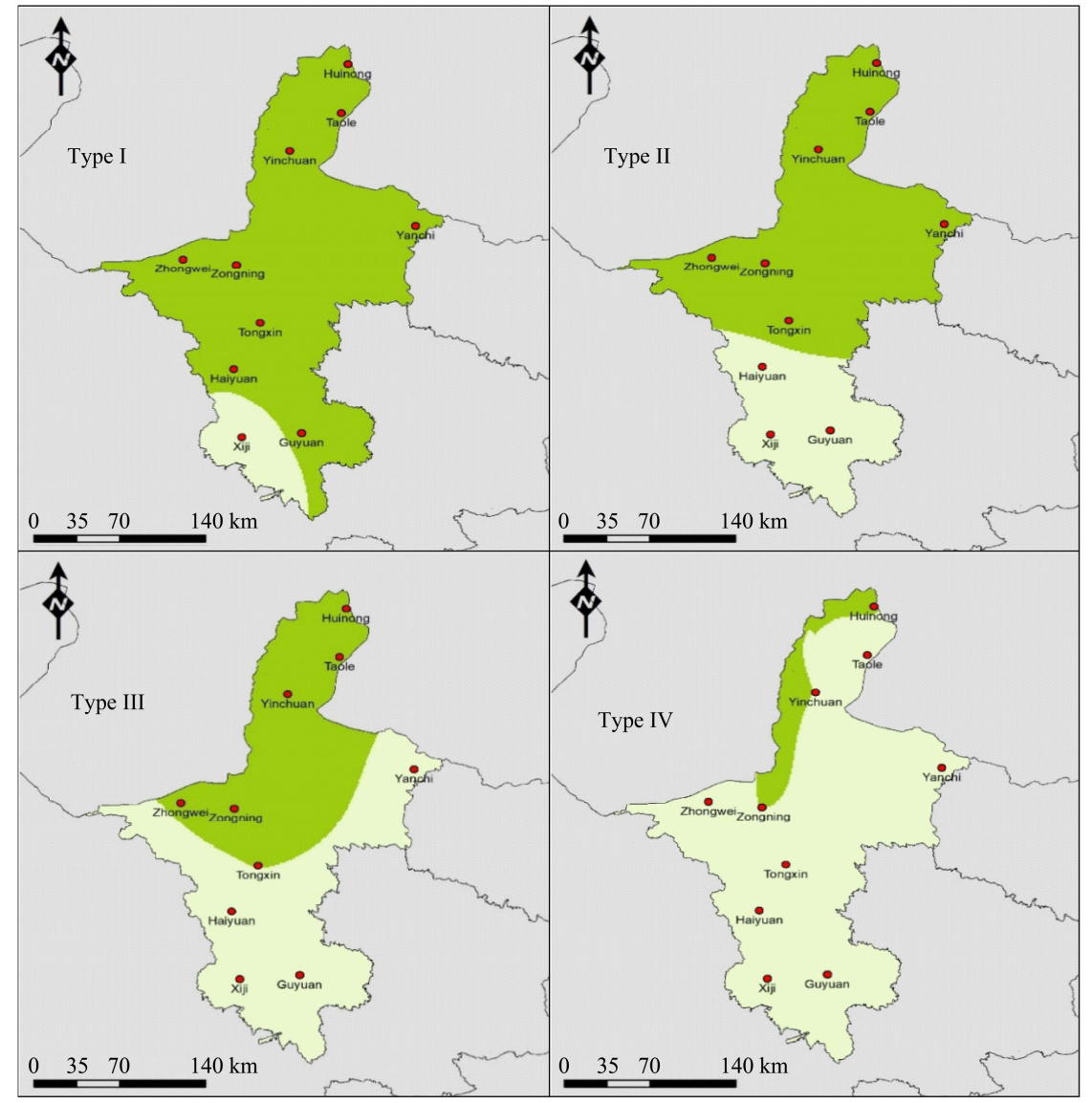

b. Distribution map of different types cultivars maize kernels dehydration to $20 \%$ in the Ningxia Hui Autonomous Region, China

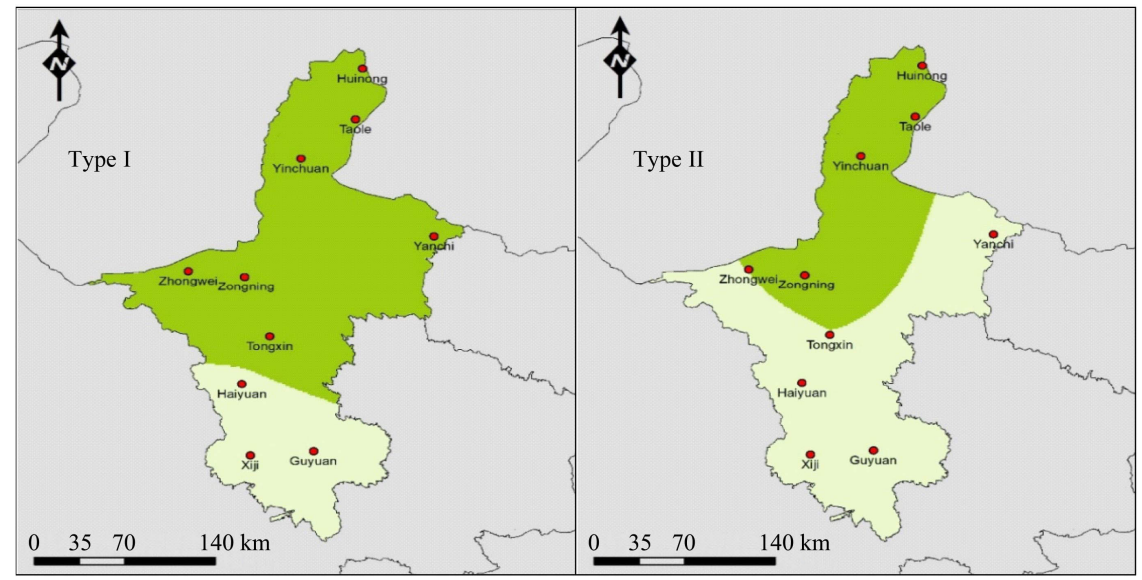

c. Distribution map of different types cultivars maize kernels dehydration to $16 \%$ in the Ningxia Hui Autonomous Region, China Figure 4 Distribution map of different types cultivars maize kernels dehydration to $25 \%, 20 \%$, and $16 \%$ in the Ningxia Hui Autonomous Region, China 
Table 6 Moisture content and broken rate of kernels harvested at the end of October in Lingwu City, Pingluo County, and Yinchuan City

\begin{tabular}{|c|c|c|c|c|c|c|}
\hline & & KX9384 (II) & Yinyu 274 (II) & Dika 517 (III) & Xianyu 335 (III) & Yinyu 439 (IV) \\
\hline \multirow{3}{*}{ Kernel moisture content $/ \%$} & Pingluo & $16.8 \pm 0.0$ & $22.5 \pm 0.4$ & $18.4 \pm 0.3$ & \multirow{3}{*}{$22.0 \pm 0.4$} & \multirow{3}{*}{$24.2 \pm 0.2$} \\
\hline & Yinchuan & $16.9 \pm 0.2$ & $22.2 \pm 0.1$ & $20.2 \pm 0.1$ & & \\
\hline & Lingwu & $14.6 \pm 0.1$ & $18.6 \pm 0.2$ & $16.6 \pm 0.3$ & & \\
\hline \multirow[b]{2}{*}{ Kernel broken rate/\% } & Pingluo & $3.1 \pm 0.4$ & $4.1 \pm 0.1$ & $2.5 \pm 0.3$ & \multirow[b]{2}{*}{$8.8 \pm 1.0$} & \multirow[b]{2}{*}{$6.3 \pm 0.7$} \\
\hline & Yinchuan & $4.6 \pm 0.4$ & $3.8 \pm 0.6$ & $4.4 \pm 0.1$ & & \\
\hline
\end{tabular}

\section{Discussion}

4.1 Relationship between the yield and required accumulated temperature for dehydration to a kernel moisture content of $\mathbf{2 5 \%}$ for different maize cultivars

Studies have shown that the yield of maize cultivars is positively correlated with the accumulated temperature during the whole growing period ${ }^{[15]}$. Gong et al. ${ }^{[18]}$ studied six maize cultivars at early maturity, middle maturity, and late maturity, and found that the required accumulated temperature from sowing to maturity was directly proportional to the yield. It has been found that, compared to early-maturing cultivars, late-maturing cultivars require more accumulated temperature during the growing period, have longer filling stages, and have a significantly higher yield. In the present study, the relationship between the yield and the required accumulated temperature of the 33 cultivars which were investigated for yield during the whole growth period was found to be $y=6.3765 x-4700.5(R=0.54$, significant at $p<0.05)$. Additionally, for cultivars of types I-III, a significant positive correlation was observed between the yield and the accumulated temperature required for kernel dehydration to a moisture content of $25 \%$.

\subsection{Effect of kernel moisture content on economic return}

Excessive moisture content in maize kernels not only affects the quality of mechanical harvesting but also greatly increases the risk of mildew and kernel breakage during later storage and transportation, increases drying costs, and reduces maize quality ${ }^{[19,20]}$. It had been reported that, in Canada, when the kernel moisture content exceeds $25 \%$, the drying cost is 24 Canadian dollars per ton of maize ${ }^{[3]}$. In parts of China, such as Gansu Province, the Xinjiang Uyghur Autonomous Region (XUAR), and the NHAR, the cost of drying maize kernels with a moisture content greater than $28 \%$ to moisture contents of $14 \%-16 \%$ is about 20-40 RMB/t. Therefore, there is a large difference in the sale price of maize kernels with high moisture content (25\%-30\%) compared to those with low moisture content (14\%-16\%). In the XUAR, the unit sale price of maize kernels with high moisture content is about $1.25-1.30 \mathrm{RMB} / \mathrm{kg}$, while that for maize kernels with low moisture content is about $1.5-1.6 \mathrm{RMB} / \mathrm{kg}$. After deducting about $0.02 \mathrm{RMB} / \mathrm{kg}$ for drying costs, drying $1 \mathrm{~kg}$ of maize kernels (14\% moisture content) can increase profit by about $0.062 \mathrm{RMB} / \mathrm{kg}$. In the NHAR, the unit sale price of maize kernels with high moisture content is about $1.5-1.6 \mathrm{RMB} / \mathrm{kg}$, while that of maize with a low moisture content can exceed $1.9 \mathrm{RMB} / \mathrm{kg}$. In the NHAR, assuming a unit price of RMB $1.977 / \mathrm{kg}$ and a drying cost of RMB $0.027 / \mathrm{kg}$, after maize kernels are dried, the economic benefit will increase by about RMB $0.115 / \mathrm{kg}$. The results of this study suggest that, in the NHAR, after maize kernels are dried, per hectare profits will increase by RMB 1453-2196. If the maize is dehydrated from a kernel moisture content of $28 \%$ to a kernel moisture content of $14 \%$ in the field after physiological maturity, a drying cost per hectare of RMB 341 to 515 will be saved, which can reduce carbon dioxide emissions by about $1.08 \mathrm{t}$. It is calculated that an accumulated temperature of $1{ }^{\circ} \mathrm{C} \cdot \mathrm{d}$ can save a drying cost of about RMB $0.63 / \mathrm{hm}^{2}$ during the air-drying of maize in the field in Ningxia.

The results of this study indicated that the following method can further increase economic benefits under mechanical grain harvesting (with grain dehydration to a moisture content of below 28\%): (1) The selection of high-yield (e.g., type III varieties in this study) and fast-dehydrating varieties. Of these two properties, high yield is of chief importance. (2) Selling when the grain has been dehydrated to a moisture content of below $16 \%$. A better way of achieving such grain dehydration is to postpone the harvest date as much as possible rather than drying after the harvest at physiological maturity since this can save some drying costs.

\subsection{Adaptability of maize varieties}

In Ningxia, the accumulated temperature was between $2851.0^{\circ} \mathrm{C} \cdot \mathrm{d}$ and $3943.5^{\circ} \mathrm{C} \cdot \mathrm{d}$ from normal sowing date to the end of October in 10 sites. In this study, the accumulated temperature requirements from sowing to physiological maturity were between $2720^{\circ} \mathrm{C} \cdot \mathrm{d}$ to $3543^{\circ} \mathrm{C} \cdot \mathrm{d}$ of 38 maize varieties. Therefore, suitable cultivars can be selected to mature and achieve low water harvest of the kernel. In Huinong, Taole, Yinchuan, Zhongning, Zhongwei, and Tongxin site of the Yellow River irrigation area, cultivars of type I-IV (i.e., a total of 32 cultivars) could be dehydrated to a kernel moisture content of $25 \%$ by the end of October. Cultivars of types I and II could be dehydrated to a moisture content of below $16 \%$. In Yanchi, the planting of type I-III cultivars could achieve dehydration to a moisture content of below $25 \%$ (i.e., a total of 20 cultivars). In Haiyuan and Guyuan, the planting of type I cultivars could achieve dehydration to a moisture content of below $20 \%$ (i.e., a total of two cultivars). On October 28,2018 , the lodging rate is less than $10 \%$ in the $65 \%$ of varieties. Therefore, some of the varieties analyzed in this study can be planted in Ningxia in order to popularize mechanical maize grain harvesting technology in this region.

\subsection{Main uncertainties in this study}

Based on an analysis of the yield and lodging rate of 33 maize cultivars in Ningxia, the planting of cultivars with a low lodging rate and high yield was recommended to facilitate the mechanical harvesting of maize kernels. Maize dehydration, plant lodging risk, and yield are affected by many factors, among which maize variety is the key factor, and each factor has a different degree of influence in different regions ${ }^{[7,18,21-25]}$. According to the environmental characteristics of the study region, the cultivars with high yield, low lodging rate, and fast dehydration was chosen for mechanical kernel harvesting.

The average accumulated temperature in Yinchuan City from April 1to October 31 in $2008-2017$ was $4001^{\circ} \mathrm{C} \cdot \mathrm{d}$, while the 
maximum and minimum accumulated temperatures were $4091{ }^{\circ} \mathrm{C} \cdot \mathrm{d}$ and $3883^{\circ} \mathrm{C} \cdot \mathrm{d}$, respectively. The accumulated temperature in Yinchuan City from April 1 to October 31 in 2017 was $4091^{\circ} \mathrm{C} \cdot \mathrm{d}$. The accumulated temperature in Yinchuan City from April 1 to October 31 in 2018 was $4036^{\circ} \mathrm{C} \cdot \mathrm{d}$. The accumulated temperature from April 1 to October 31 in 2017 and 2018 was higher than the average accumulated temperature in $2008-2017$ by $90^{\circ} \mathrm{C} \cdot \mathrm{d}$ and $35^{\circ} \mathrm{C} \cdot \mathrm{d}$, respectively. Therefore, in colder years and places, the growth and dehydration of maize will slow. The work of our research group shows that accumulated temperature of silking-dehydration to a certain moisture content was very consistent with Equation (3); however, not all $\geq 0^{\circ} \mathrm{C}$ temperatures are effective for maize growth and development, and when the temperature is very high or low, the mature period of maize varieties should be paid attention.

\section{Conclusions}

In this study, it was found that, in 33 maize cultivars, the relationship between the yield and the accumulated temperature required for kernel dehydration to a moisture content of $25 \%$ followed: $y=6.4581 x-4911.3$, where $y$ is the yield and $x$ is the required accumulated temperature, and where $2800^{\circ} \mathrm{C} \cdot \mathrm{d}<x<$ $3400^{\circ} \mathrm{C} \cdot \mathrm{d}$. Planting cultivars that dehydrate extremely quickly can save on drying costs, however, the yield and overall profits are low. Very low yields lead to very low economic returns. Therefore, high-yield cultivars should be planted among cultivars that can dehydrate to a kernel moisture content of less than $25 \%$, and the maize kernel dehydration time in the field should be extended to save costs.

\section{Acknowledgements}

This research was supported by the National Key Research and Development Program of China (2016YFD0300110), the National Natural Science Foundation of China (31971849), the National Maize Industrial Technology System of China (CARS-02), the Science and Technology Innovation Project of the Chinese Academy of Agricultural Science and the Key Research and Development Program of Ningxia (2018BBF02018) for their financial support.

\section{[References]}

[1] Li S K. Factors affecting the quality of maize grain mechanical harvest and the development trend of grain harvest technology. J Shihezi Univ (Nat Sci), 2017; 35(3): 265-272. (in Chinese)

[2] Fang H M, Niu M M, Shi S, Liu H, Zhou J. Effect of harvesting methods and grain moisture content on maize harvesting quality. Transactions of the CSAE, 2019; 35(18): 11-18. (in Chinese)

[3] Lackery R. Corn energy value-a comparison of harvesting corn as shelled dried corn, high moisture corn, high moisture cob corn (cob meal) and corn silage. Ministry of Agriculture Food and Rural Affairs, 2008. http://www.omafra.gov.on.ca/english/livestock/beef/news/vbn1108a2.htm. Accessed on [2017-02-06]

[4] Chai Z W, Wang K R, Guo Y Q, Xie R Z, Li L L, Hou P, et al. Current status of maize mechanical grain harvesting and its relationship with grain moisture content. Sci Agric Sin, 2017; 50(11): 2036-2043. (in Chinese)

[5] Li L L, Xue J, Xie R Z, Wang K R, Ming B, Hou P, et al. Effects of grain moisture content on mechanical grain harvesting quality of summer maize. Acta Agron Sin, 2018; 44(12): 1747-1754. (in Chinese)

[6] Raben J, Humphreys W, Boydston B, Duvall D, Ulibarri V, Schwarck R, et al. The corn harvest quality report. The U.S. Grains Council, 2011-2019. https://grains.org/corn_report. Accessed on [2019-12-26]

[7] Brooking I R. Maize ear moisture during grain-filling, and its relation to physiological maturity and grain-drying. Field Crop Res, 1990; 23(1): 55-68.

[8] Hunter R B, Mortimore G, Gerrish E E, Kannenberg L W. Field drying of flint and dent endosperm maize. Crop Sci, 1979; 19(3): 401-402.

[9] Waelti H. Physical properties and morphological characteristics of maize and their influence on threshing injury of kernels. Ames: Iowa State University, 1967.

[10] Wang K R, Li S K. Progresses in research on grain broken rate by combine harvesting maize. Sci Agric Sin, 2017; 50(11): 2018-2026. (in Chinese)

[11] Plett S. Corn kernel breakage as a function of grain moisture at harvest in a prairie environment. Canada J Plant Sci, 1994; 74: 543-544.

[12] Chowdhury M H, Buchele W F. The nature of corn kernel damage inflicted in the shelling crescent of grain combines. Trans ASAE, 1978; 21(4): 610-614.

[13] Li L L, Ming B, Xie R Z, Wang K R, Hou P, Li S K. The establishment of dehydration type and mechanical grain collecting time of yellow-Huaihai Summer maize. Acta Agron Sin, 2018; 44(12): 1764-1773. (in Chinese)

[14] Mederski H J, Miller M E, Weaver C R. Accumulated heat units for classifying corn hybrid maturity. Agron J, 1973; 65: 743-747.

[15] Zhang W X, Ming B, Wang K R, Li C W, Hou P, Cheng J L, et al. Analysis of the suitable sowing time and harvesting period of machine-harvested maize based on the characteristics of mature period and grain dehydration. Sci Agric Sin, 2018; 51(10): 1890-1898. (in Chinese)

[16] Daynard T B. Relationships among black layer formation, grain moisture percentage, and heat unit accumulation in corn. Agron J, 1972; 64: 716-719.

[17] Huang Z F, Ming B, Wang K R, Xie R Z, Yang F, Wang Z G, et al. Characteristics of maize grain dehydration and prediction of suitable harvest period in Liao River Basin. Acta Agron Sin, 2019; 45(6): 922-931. (in Chinese)

[18] Gong X J, Qian X R, Yu Y, Jiang Y B, Hao Y B, Li L, Ge X L. Effects of different sowing date on grain yield and yield components of spring maize. J Maize Sci, 2019; 27(3): 108-113. (in Chinese)

[19] Paulsen M R, Nave W R. Corn damage from conventional and rotary combines. Bmc Gastroenterol, 1980; 23(5): 1110-1116.

[20] Dutta P K. Effects of grain moisture, drying methods, and variety on breakage susceptibility of shelled corns as measured by the Wisconsin Breakage Tester. Ames: Iowa State University, 1986.

[21] Wang K R, Li S K. Analysis of influencing factors on kernel dry-down-rate of maize hybrids. Sci Agric Sin, 2017; 50(11): 2027-2035. (in Chinese)

[22] Cross H Z. Leaf expansion rate effects on yield and yield components in early-maturing maize. Crop Sci, 1991; 31(3): 579-583.

[23] Magari R, Kang M S, Zhang Y. Sample size for evaluating field ear moisture loss rate in maize. Maydica, 1996; 41(1): 19-24.

[24] Xue J, Wang K R, Xie R Z, Gou L, Zhang W F, Ming B, et al. Research progress of maize lodging during late stage. Sci Agric Sin, 2018; 51(10): 1845-1854. (in Chinese)

[25] Xue J, Li L L, Xie R Z, Wang K R, Hou P, Ming B, et al. Effect of lodging on maize grain losing and harvest efficiency in mechanical grain harvest. Acta Agron Sin, 2018; 44(12): 1774-1781. (in Chinese) 